\title{
Mobility as a feature: Evidence from Zulu*
}

\author{
Jochen Zeller \\ Linguistics Programme, University of KwaZulu-Natal, Durban, South Africa \\ E-mail: zeller@ukzn.ac.za
}

\begin{abstract}
This paper provides evidence for the view that syntactic movement of an element $\mathrm{Y}$ to a position $\mathrm{X}$ is not driven by features of the target $\mathrm{X}$, but by features of the moving element $\mathrm{Y}$. The data that constitute evidence for this type of analysis come from A-bar movement constructions (object left and right dislocation; object relativisation) in the Bantu language Zulu. As I show, only object-DPs that move out of the VP in Zulu are active Goals for Agreerelations and can trigger object agreement with the verb. The fact that the functional head responsible for object agreement must be able to identify a DP in its c-command domain as an active Goal entails that the "mobility" of this DP must be encoded as a property of the DP. Based on this conclusion, I also discuss two proposals about the nature of the feature that activates a DP for movement in Zulu and examine the conditions that determine how this feature is checked and deleted through movement.
\end{abstract}

Keywords: syntactic movement; EPP-features; Zulu; dislocation; relative clauses

\section{Introduction}

The standard view in the Minimalist Program since Chomsky $(2000,2001)$ is that syntactic movement is driven by (so-called EPP- or edge) features of a functional head $\mathrm{F}$ that attract a phrase XP to move to F's specifier. However, an alternative position held by various authors is that the "mobility" of XP (i.e. the property of having to undergo movement) is encoded on the XP itself. Accordingly, it is a feature associated with the head of XP that causes XP to be repelled from its base position.

In light of this debate about the trigger for syntactic movement, I revisit the empirical data and theoretical conclusions discussed in my recent work on $\mathrm{A}^{\prime}$-movement in the Bantu language

\footnotetext{
"I wish to thank Erich Groat, Claire Halpert, the audience of SAMWOP-3, and two anonymous reviewers for helpful comments and discussion of the empirical and theoretical material presented in this paper and in earlier versions thereof. I also thank my Zulu consultants Nothando Mzulwini, Thandeka Maphumulo and Mthuli Buthelezi for their judgements. I am fully responsible for all errors that remain. This work is based on the research supported by the National Research Foundation (NRF). Any opinion, finding and conclusion or recommendation expressed in this material is that of the author and the NRF does not accept any liability in this regard.
} 
Zulu (Zeller 2014, 2015). Specifically, I argue that my earlier findings provide evidence for the view that movement is induced by a feature of the moved element. In Zeller (2014, 2015), I show that in Zulu, only object-DPs that have undergone movement out of the VP are accessible Goals for object agreement. In contrast, objects that remain in the VP are not "visible" to a probing head; they never agree, and they do not act as intervenors for object agreement in terms of locality principles. I now demonstrate that these facts follow directly from the idea that the "mobility" property of a DP is encoded on the DP itself and, importantly, that it is this very property that makes the DP "visible" to agreement relations. The concrete claim that I defend in this article is therefore that object-DPs in Zulu may optionally be equipped with an uninterpretable feature with a dual purpose: it repells the DP from its base position and forces it to move out of the VP, but at the same time, it activates the DP and turns it into an accessible Goal for the probing head associated with object agreement in Zulu.

In section 2, I discuss the standard analysis of agreement and movement in the Minimalist Program, focusing on the status of EPP- and edge features in Chomsky's work between 2000 and 2013, and contrasting this attract-based account of movement with the repel-based analyses of Bošković (2007) and Stroik (2009). Section 3 focuses on different A'-movement constructions in Zulu, which demonstrate that only ex situ DPs in Zulu are potential targets for object agreement. I complement my earlier empirical observations regarding Zulu right dislocation and relativisation (Zeller 2014, 2015) with new data from left dislocation and Quantifier Raising (QR), and I show that these data follow from the idea that (overt) A'movement in Zulu is driven by a feature of the moved element. Section 4 offers some speculations about the nature of the feature that activates a DP for movement and agreement in Zulu, and section 5 concludes the paper.

\section{The trigger for movement}

\subsection{Movement as attraction}

In the Minimalist Program (MP), agreement between DPs and functional heads is analysed in terms of the operation Agree (Chomsky 2000, 2001). Agree establishes a relation between a Probe P (an unvalued uninterpretable feature) and the closest Goal G (the corresponding valued interpretable feature) in the c-command domain of the Probe. For example, when the $\varphi$-features (person, number, gender) of T probe T's c-command domain, they locate the $\varphi$ features of the subject-DP in [Spec, $v$ ] as the closest matching Goal, and the two will Agree:

(1)

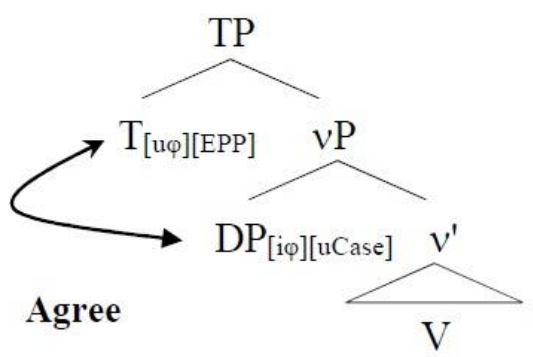

In order for the interpretable feature(s) of a category $\mathrm{Y}$ to count as an accessible Goal, $\mathrm{Y}$ must also have an uninterpretable feature, which activates $\mathrm{Y}$ for Agree. In (1), the activating feature of the subject-DP is the uninterpretable structural Case feature [uCase]. When Agree is 
established, the uninterpretable features of $\mathrm{T}$ and DP are valued/checked, and then deleted in the mapping to LF.

As (1) shows, Agree does not require a Spec-Head relation between the functional head and the agreeing DP, but can take place at a distance (as long as Locality is not violated; see section 3). For example, it is well-known that subjects can remain in their base positions in many languages and still trigger subject agreement on the verb or auxiliary, as in English existential constructions such as (2a), which is based on the syntax shown in (1):

(2) a. There are [vp people in the garden]

b. People are [vp people in the garden]

Since Agree does not require movement, additional assumptions are necessary to derive sentences such as (2b), in which the subject has moved to [Spec, T]. According to the view expressed in Chomsky $(2000,2001)$, syntactic movement is triggered if the probing head also has an EPPfeature, which forces the projection of a specifier. Finite $T$ in English is typically taken to have an EPP-feature; ${ }^{1}$ it can be checked by an expletive when the subject remains in $v P$, as in (2a), or it triggers movement of the subject-DP to [Spec, T] to derive (2b), as shown in (3):

(3)

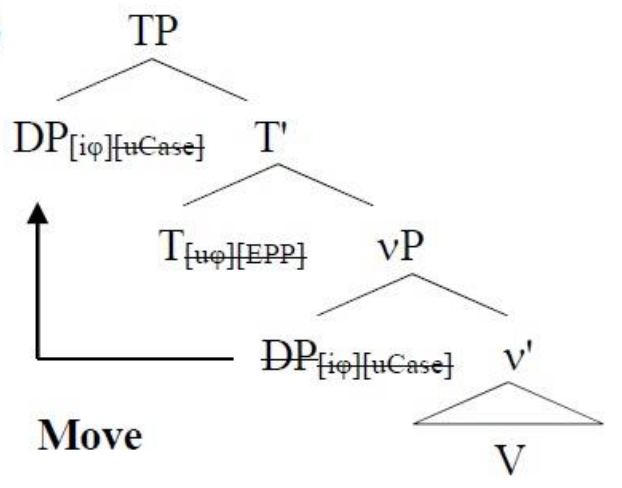

According to Minimalist theories that assume EPP-features, syntactic movement is therefore a case of attraction: movement of a phrase to the specifier of a head $\mathrm{F}$ is triggered by a feature of $\mathrm{F}$ (the EPP).

The nature of, and the motivation behind, the "mysterious property EPP" (Chomsky 2008: 156) have been much debated in the MP (see e.g. Bošković 2002, 2007; Epstein and Seely 2006; Grohmann, Drury and Castillo 2000). Chomsky (2013) offers a novel motivation for this property based on his labelling algorithm. The label of a syntactic object SO derived by Merge determines which of the two merged elements projects. When the subject-DP merges with a projection of $v$, the resulting $\mathrm{SO}$ is a set of the form $\{\mathrm{DP}, v \mathrm{P}\}$. This set needs a label to be identifiable as being either of category $\mathrm{D}$ or $\mathrm{v}$. However, according to the labelling algorithm proposed in Chomsky (2013), SO cannot be labelled, since neither of the two members of the set is a "computational atom", i.e. a head. But the problem can be solved by A-movement: when the subject moves to [Spec, T], it is no longer "visible" as part of SO (the lower copy of the subject doesn't count), and the label of SO can be identified as $v$. The

\footnotetext{
${ }^{1}$ The issue is more controversial regarding non-finite T. See e.g. Bošković $(2002,2007)$, Chomsky (1995, 2000, 2001), Epstein and Seely (2006), Grohmann, Drury and Castillo (2000), among others, for discussion.
} 
labelling algorithm hence provides an independent motivation for why a subject-DP must raise to [Spec, T]. Since this movement step is triggered by an EPP-feature, the presence of this feature on $\mathrm{T}$ follows from labelling.

In early versions of the MP, it was assumed that both A-movement and A'-movement involve Probe-Goal relations and attracting features. For example, wh-constructions were analysed in terms of an Agree-relation between an uninterpretable [uQ]-feature of $\mathrm{C}$ (the Probe) and the interpretable [iQ]-feature of a wh-phrase (the Goal); wh-phrases were assumed to be activated by having uninterpretable wh-features ([uwh]), and overt wh-movement was triggered by an EPP-feature of $\mathrm{C}$ that would attract the wh-phrase to [Spec, C] (see e.g. Chomsky 2000; Grewendorf 2001). However, in later work, Chomsky $(2007,2008)$ dispenses with the idea that A'-movement requires Agree-relations. Instead, Chomsky suggests that $\mathrm{A}^{\prime}$-movement is solely driven by EPP-features of phase heads (now called edge features EF): ${ }^{2}$

Suppose that the edge-feature of the phase head is indiscriminate: it can seek any goal in its domain, with restrictions $[\ldots]$ determined by other factors [...]. Take, say, Topicalization of DP. EF of a phase head PH can seek any DP in the phase and raise it to SPEC-PH. [...] what is raised is identified as a topic by the final position it reaches, and any extra specification is redundant. The same should be true for other forms of A'-movement. We need not postulate an uninterpretable feature that induces movement.

(Chomsky 2008: 151)

According to this view, a discourse-related interpretation associated with a particular type of $\mathrm{A}^{\prime}$-movement such as topicalisation is established as a result of movement, and no longer requires an Agree-relation between uninterpretable features of the target and the moving category. A'-movement is solely driven by EF of the phase head, which attracts a constituent and moves it to the edge of the phase.

The picture that emerges from these views is that both A- and A'-movement in current Minimalist theory can be analysed as being driven by EF/EPP-features of an attracting head. The presence of these attracting features is required for reasons that are independent of Agree. A-movement takes place to provide a SO with a label; A'-movement establishes semantic or discourse-related properties of the construction, but neither of these movement operations require the attracting head and the head of the moved constituent to be involved in an Agree-relation.

\footnotetext{
2 According to phase theory, derivations proceed in cycles, with each cycle corresponding to a subsection of the derivation called a phase. According to Chomsky $(2000,2001)$, phase heads are transitive $v$ and $\mathrm{C}$ (but see Bošković (2014) and the references cited therein for different views). When a phase is completed, the complement of the phase head is transferred to the PF and LF interfaces and is therefore no longer accessible for operations triggered by material outside the phase (the Phase Impenetrability Condition PIC; see (6) below in the text). Therefore, material from within the phase must first move to the edge of the phase (its specifier) to remain accessible to operations triggered in the next phase.
} 


\subsection{Movement as repulsion}

The view that movement operations are triggered by attracting features of the target is not uncontroversial and has been challenged by various authors in recent years. An alternative proposal is put forward in Bošković (2007). This proposal is based on the idea (mentioned in section 2.1 above) that certain uninterpretable features can activate elements for syntactic operations. Recall that, according to Chomsky (2000, 2001), DPs are activated for Agree by virtue of their uninterpretable Case feature [uCase], while wh-phrases might be activated for Agree by [uwh]. However, according to Bošković (2007), elements are not activated for Agree, but for movement. To this end, Bošković postulates a feature [uK] that can optionally be realised on a phrase $\mathrm{Y}$ when $\mathrm{Y}$ enters the derivation. The precise nature of $[\mathrm{uK}]$ depends on the type of phrase and the type of movement (see section 4 for discussion), but crucially, [uK] marks a phrase as having to undergo movement (in Bošković's (2007: 619) words, "the uK on Y essentially says, 'I am moving!'”). This means that movement does not require an attracting $\mathrm{EF}$ or EPP-feature of the landing site, but is driven by a property of the moved category.

In Bošković's (2007) theory, the link between the presence of [uK] on Y and the requirement that Y must move is not simply stipulated, but follows from Last Resort and the inherent constraints of derivations based on the concept of a phase. In order to see why movement of $Y$ is an automatic consequence of $[\mathrm{uK}]$ on $\mathrm{Y}$, two cases need to be considered. The first concerns instances where a matching Goal-feature for $[\mathrm{uK}]$ (henceforth $[\mathrm{iK}]$ ) is located within the smallest phase $\alpha$ which includes $\mathrm{Y}$. [uK], being an uninterpretable feature, must act as a Probe in an Agree-relation with this Goal. As noted by Bošković (2007), the standard assumption that Probes must c-command their Goals (see section 2.1) therefore implies that Y must move to the closest position from where it c-commands [iK] (cf. Epstein, Groat, Kawashima and Kitahara 1998, Epstein and Seely 2006). If [iK] is in X, then Y must move at least to $[$ Spec, $\mathrm{X}]$ :

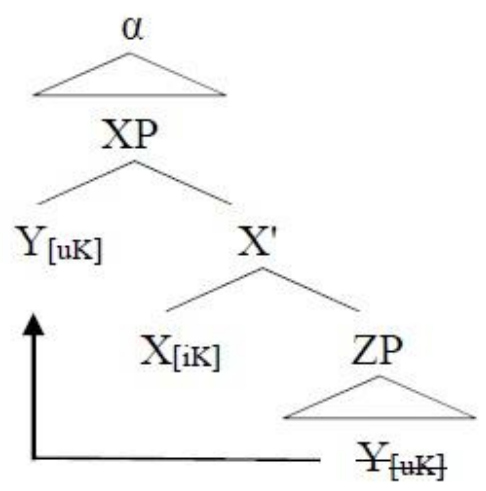

As (4) shows, without movement of $\mathrm{Y},[\mathrm{uK}]$ on $\mathrm{Y}$ will not find $[\mathrm{iK}]$ in its c-command domain. Therefore, the presence of [uK] on $\mathrm{Y}$ forces movement of $\mathrm{Y}$ as a Last Resort operation to guarantee that $[\mathrm{uK}]$ will be checked and deleted.

The second case to consider is successive-cyclic movement of Y to a position outside phase $\alpha$ : 
(5)

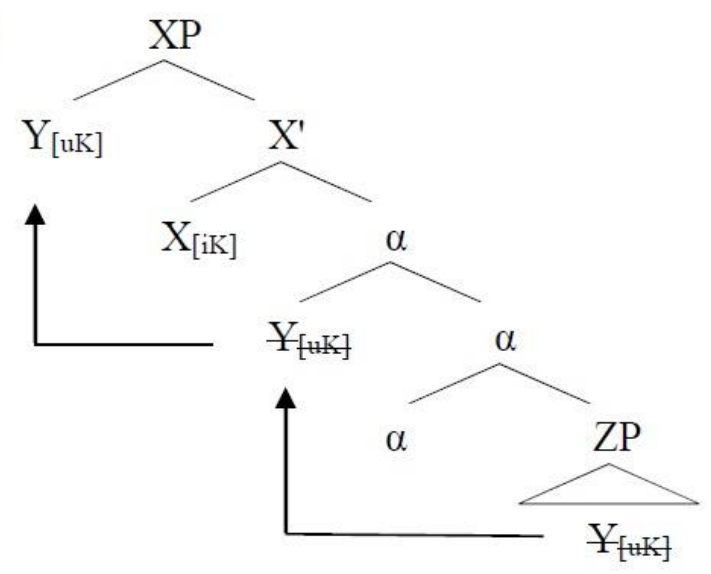

In (5), $\mathrm{Y}$ has $[\mathrm{uK}]$, but the Goal-feature $[\mathrm{iK}]$ is associated with a head $\mathrm{X}$ outside $\alpha$. Therefore, in order to reach a position from where $\mathrm{Y}$ c-commands $\mathrm{X}, \mathrm{Y}$ will first have to move to the edge of $\alpha$, as required by the Phase-Impenetrability Condition (PIC), defined as in (6) by Chomsky (2000: 108):

\section{(6) Phase-Impenetrability Condition}

In phase $\alpha$ with head $H$, the domain of $H$ is not accessible to operations outside $\alpha$, only $\mathrm{H}$ and its edge are accessible to such operations.

It is important to note that in a strictly bottom-up derivation, Y will move to the edge of $\alpha$ in (5) before the head X, which bears the Goal-feature, is introduced in the next phase. However, as Bošković (2007) points out, a look-ahead problem nevertheless does not arise in his theory. Last Resort requires $\mathrm{Y}$ to move to the edge of $\alpha$ even if $\alpha$ does not include a matching Goal for [uK], because without movement, $[\mathrm{uK}]$ will definitely remain unchecked. If Y remains in the domain of $\alpha$, it will be transferred to the interfaces as soon as $\alpha$ is complete and cannot be moved into the next phase. Therefore, Y must move to "help itself" (Bošković 2007: 610); it must reach the edge of $\alpha$ to remain accessible, anticipating the possibility that a potential Goal that can check [uK] will eventually be part of a higher phase. As Bošković (2007) emphasises, there is no feature checking relation between $\mathrm{Y}$ and the head of $\alpha$ in constructions such as (5); successivecyclic movement does not require the postulation of otherwise unmotivated features associated with intermediate landing sites. Successive-cyclic movement nevertheless follows from Last Resort, because [uK] will not be deleted without movement of Y, given the PIC.

In a nutshell, $[\mathrm{uK}]$ activates $\mathrm{Y}$ for movement, regardless of whether or not a suitable Goal is part of Y's phase. If there is one, then Y needs to bring [uK] into a position from where it ccommands the Goal; if there is not, then Y must move to the phase edge to remain accessible and part of the derivation.

Bošković's (2007) analysis is similar in important respects to the account offered in Stroik (2009) (although the details of the two proposals differ). Like Bošković, Stroik (2009) argues that movement is not driven by attracting features, but by a feature of the moved element. According to Stroik's (2009) Survive Principle, if an element Y has a feature that cannot be checked in the configuration in which $\mathrm{Y}$ is merged, the feature "survives" this configuration, and $\mathrm{Y}$ is repelled from its base and moves to the next available landing site. If feature checking is not possible in this position either, $\mathrm{Y}$ will be repelled from this position 
again, and move further, until it appears in a position in which all of its features can be checked (i.e. $\mathrm{Y}$ will move successive-cyclically until there are no survivors). The Survive Principle also explains movement without the need for attracting features. Rather, movement is repulsion: an element $\mathrm{Y}$ with an unchecked feature is pushed up in the derivation until it reaches a position where its feature can be checked.

To sum up this section, in Chomsky's attract-based theory as well as in Bošković's (2007) and Stroik's (2009) repel-based accounts, movement is captured through the postulation of an uninterpretable feature. The two approaches differ in whether this feature is associated with the target of movement (EPP/EF), or with the moved element ([uK]). In the next section, I provide empirical evidence in favour of the latter type of analysis, by showing that in the Bantu language Zulu, the "mobility" of a phrase is encoded by a grammatical feature on the moving category.

\section{3. $\quad A^{\prime}$-movement in Zulu and Agree}

\subsection{Right dislocation and object agreement}

In simple ditransitive constructions such as (7), a beneficiary (or goal) DP obligatorily precedes the theme-DP in Zulu: ${ }^{3}$
$\begin{array}{ll}\text { a. } & \text { Ngi-theng-el-a } \\ \text { 1s-buy-APPL-FV } & \text { AUG-1a.Sipho }\end{array}$
'I'm buying milk for Sipho.'
b. *Ngi-theng-el-a u-bisi u-Sipho.
1s-buy-APPL-FV AUG-11.milk AUG-1a.Sipho

I assume, following Marantz (1993), that word order in the VP reflects c-command in Bantu. Therefore, (7) shows that beneficiary-DPs c-command theme-DPs in Zulu.

Either object-DP of a double object construction can be object-marked in Zulu (Adams 2010; Zeller 2012, 2015):
a. Ngi-m-theng-el-a u-bisi
1S-1.OM-buy-APPL-FV AUG-11.milk
'I'm buying him milk, Sipho.'
b. Ngi-lu-theng-el-a u-Sipho
1s-11.OM-buy-APPL-FV AUG-1a.Sipho
'I'm buying it for Sipho, the milk.'

\author{
u-Sipho. \\ AUG-1a.Sipho \\ u-bisi. \\ AUG-11.milk
}

As (8a) shows, when the beneficiary DP is object-marked, the word order changes; the beneficiary must now follow the theme. This is evidence that object marking in Zulu is generally correlated with (right) dislocation of the object-marked DP to a VP-external

\footnotetext{
${ }^{3}$ Morphemes are glossed as follows: $1,2 \mathrm{~s}=$ first, second person singular; APPL = applicative; AUG = augment; $\mathrm{COP}=$ copulative; $\mathrm{DJ}=$ disjoint verb form; $\mathrm{FV}=$ final vowel; $\mathrm{OM}=$ object marker; $\mathrm{Op}=$ null relative operator; POSS = possessive; pro = null pronoun; $\mathrm{PST}=$ (recent) past tense; REL = relative marker; RS = relative suffix; $\mathrm{SM}=$ subject marker. Numbers on nouns and agreement markers indicate noun class.
} 
position, (9a). ${ }^{4}$ Both the object-marked beneficiary-DP in (8a) and the object-marked themeDP in (8b) are hence outside the VP, even though the word order does not reflect right dislocation in the latter case, $(9 b)$ :

(9)

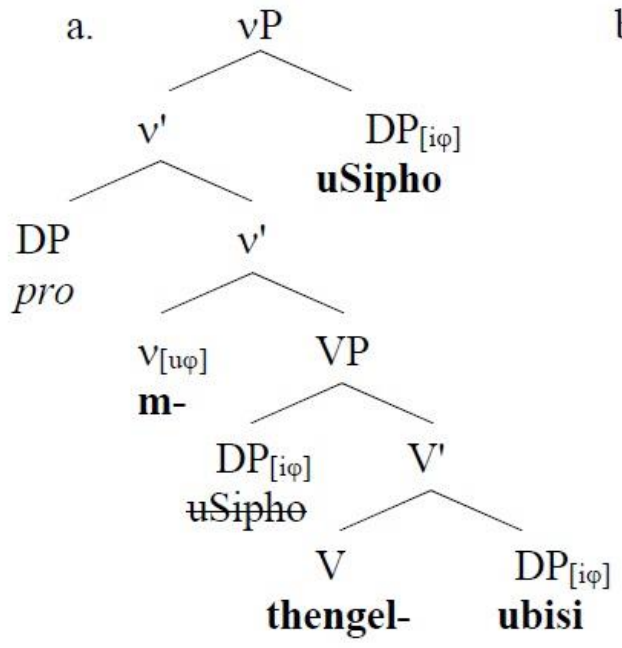

b.

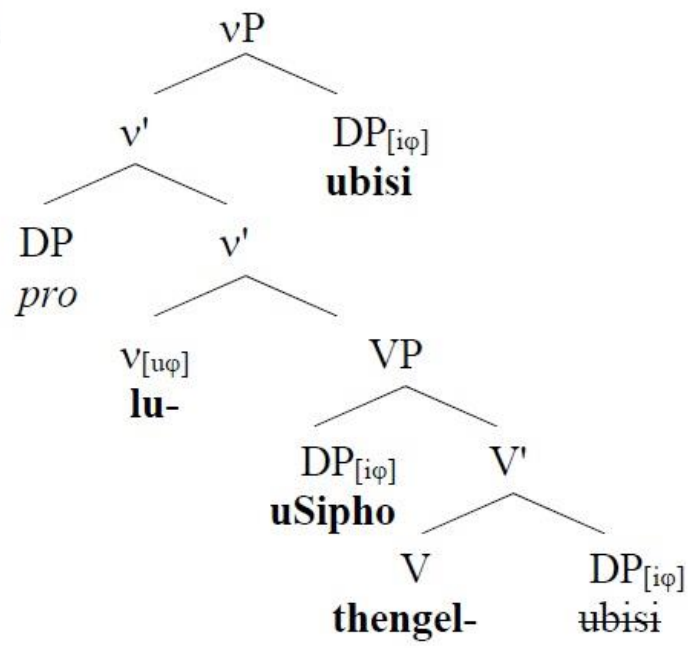

In this paper, I analyse object right dislocation as movement to the (right) edge of $v \mathrm{P}$, and I follow Chomsky $(2000,2001)$ in assuming that $v \mathrm{P}$ is a phase. In accordance with standard Minimalist assumptions, I treat object agreement as a reflex of an Agree-relation between the uninterpretable $\varphi$ - (= noun class) features [u $\varphi$ ] of $v$ and the interpretable $\varphi$-features [i $\varphi$ ] of an object-DP. ${ }^{5}$ When [u $\varphi$ ] of $v$ probes and finds an accessible Goal in its domain, the Goal-DP's [i甲]-features check and delete the Probe under Agree. Furthermore, I follow Chomsky (2000) and assume that for an object-DP to be an accessible Goal for $\varphi$-feature agreement, it needs an uninterpretable feature to be activated for Agree (see section 2.1). Importantly, as I argue below, the feature that activates a DP for agreement in Zulu is the same feature that also activates it for movement.

A question that arises from (9) is why the probing [u $\varphi$ ] of $v$ can Agree with [i $\varphi$ ] of the themeDP in (9b), although the [i $\varphi]$-features of the beneficiary-DP intervene between the two. Object agreement with the theme should be ruled out by Locality/Relativized Minimality (Chomsky 1995, 2000; Rizzi 1990), which expresses the fact that Agree can only be established between a Probe P and the closest matching Goal G (Chomsky 2000: 122):

(10) Locality: $\mathrm{D}(\mathrm{P})$ is the c-command domain of $\mathrm{P}$, and a matching feature $\mathrm{G}$ is closest to $\mathrm{P}$ if there is no $G^{\prime}$ in $D(P)$ matching $P$ such that $G$ is in $D\left(G^{\prime}\right)$.

\footnotetext{
${ }^{4}$ For reasons of space, I cannot review all the evidence for this generalisation here, but see Adams (2010); Buell (2005, 2006); Cheng and Downing (2009); Van der Spuy (1993) and Zeller (2012, 2015), who provide numerous arguments for the view that agreeing objects in Zulu are always outside the VP.

${ }^{5}$ The analysis illustrated in (9) is a slight departure from Zeller (2015), where I argue that the landing site of right dislocation targets the specifier of a category $\mathrm{X}$ that merges with $v \mathrm{P}$. The reason why the analysis in Zeller (2015) is probably more accurate than the one in (9) is that there is evidence that in Zulu, rightdislocated DPs are in fact outside the $\nu \mathrm{P}$, where "outside" is understood as "not c-commanded by the next head that merges with $v$ P" (cf. Halpert 2012). The analysis in (9) does not capture this fact. Nevertheless, I adopt it here for ease of exposition. Nothing in the discussion that follows hinges on whether right dislocation targets [Spec, $v]$ or $[\mathrm{Spec}, \mathrm{X}]$, and the conclusions I draw follow under both views.
} 
Since the beneficiary-DP c-commands the theme, its [i $\varphi$ ] should count as a closer Goal for [u $\varphi$ ] of $v$ and prevent object agreement with the theme-DP. However, theme agreement is possible in (8b), which suggests that Locality is not violated in this example.

Interestingly, Locality effects are observed in Zulu when both DPs are dislocated (Adams 2010; Zeller 2015):

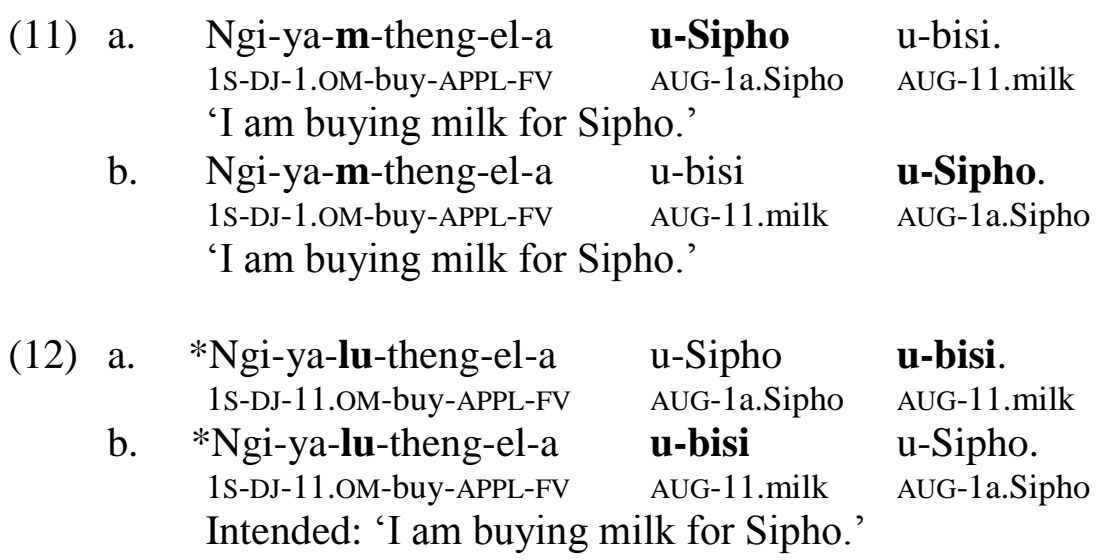

There is ample evidence that in (11) and (12), both DPs are dislocated. For reasons of space, I cannot review all the arguments here, but I will mention two (see Zeller 2015 for more evidence). Firstly, note that the DPs in (11) can appear in either order. This suggests that neither of the two objects is in its VP-internal base position, since the word order with VP-internal DPs is fixed in Zulu (see (7) and (8)). ${ }^{6}$ Secondly, observe that the verbs in (11) and (12), in contrast to the verbs in (8) above, appear in the so-called disjoint form, which in Zulu is marked by the morpheme $y a$ - in the present tense. As has been established in work by Buell $(2005,2006)$, Halpert (2012) and Van der Spuy (1993), among others, the disjoint form in Zulu is a marker of constituency: it signals that there is no VP-internal material following the verb. Therefore, the fact that ya- appears in (11) and (12) shows that neither of the two objects is inside the VP, i.e. both must be dislocated. In contrast, the disjoint marker is not present in (8a) and (8b) above, because the VP in these examples includes the non-agreeing, non-dislocated object.

Importantly, as (11) and (12) show, when both objects have moved out of the VP, object agreement with the theme is no longer possible, but can only be with the beneficiary. The crucial contrast is between the example in (8b) (which has the syntax shown in (9b) and (13)), and the example in (12a) (with the syntax in (14)):

$$
\text { Ngiluthengela } \underline{\text { uSipho }} \text { ubisi] }]_{\mathrm{VP}} \quad \text { ubisi] }
$$

\section{*Ngiyaluthengela $\mathrm{uSiph}_{\mathrm{S}}$ ubisi] $]_{\mathrm{VP}} \quad \underline{\mathrm{uSipho}}$ ubisi]}

The contrast between (13) and (14) shows that theme agreement is possible when the beneficiary (underlined in (13) and (14)) remains in situ, but impossible when this DP is dislocated. In Zeller (2015), I explain this contrast by arguing that in Zulu, only DPs that move out of the VP are accessible Goals for the functional head responsible for object agreement.

\footnotetext{
${ }^{6}$ I offer an analysis of the free word order in (11) at the end of this subsection.
} 
Therefore, when the [u甲]-features of $v$ probe $v$ 's c-command domain in $(9 b) /(13)$, they do not "see" the beneficiary, since this DP remains in the VP. The only DP in the c-command domain of $v$ that will eventually be dislocated is the theme, which therefore is the only visible Goal for the Probe in $v$. Consequently, $v$ can agree with the theme without violating Locality. However, in (11) and (12), both the theme and the beneficiary move out of the VP. Both DPs are therefore accessible Goals. Locality now determines that only the closest DP to the Probe in $v$ can agree. Since the beneficiary c-commands the theme, this entails that only the beneficiary-DP can trigger object agreement in Zulu when both DPs are dislocated. ${ }^{7}$

This is an important conclusion in light of the discussion in section 2. If $\varphi$-features of DPs are only active for Agree when the DP undergoes movement, then this means that the "I am moving!"--property must be encoded on the respective DP before the DP moves, to guarantee that its $\varphi$-features are "visible" to the Probe. This conclusion supports the view advocated by Bošković (2007) and Stroik (2009), according to which movement is triggered by a feature of the moving category.

Therefore, I propose that in constructions such as (11), both the theme and the beneficiary carry a mobility feature (which I now call [uK], following Bošković (2007)) when they are still in situ. The presence of the feature [uK] on both DPs determines that both DPs will undergo movement. But in addition, $[\mathrm{uK}]$ also activates DPs for Agree in Zulu. Accordingly, there are two active Goals in the c-command domain of the Probe $v$ in (11). Recall that object

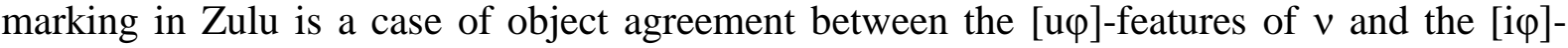
features of the closest active DP in v's c-command domain. Since both object-DPs are active in (11), Locality now determines that only the higher Goal can Agree; consequently, (12)/(14) is ungrammatical. In $(8 \mathrm{~b}) /(13)$, in contrast, only the theme-DP has $[\mathrm{uK}]$. This means that the beneficiary-DP in this example is not an active Goal for Agree, and its [i $\varphi$ ]-features therefore do not block Agree between $v$ and the theme. As a result, the theme agrees with $v$ and will move, while the beneficiary remains in the VP. Lacking $[\mathrm{uK}]$, the beneficiary is invisible for a probing head and does not produce intervention (Locality) effects. ${ }^{8}$

\footnotetext{
${ }^{7}$ A reviewer wonders if the agreement asymmetry illustrated by (11) and (12) could not simply be the result of an animacy asymmetry: the beneficiary is animate, while the theme is inanimate. However, in Zeller (2015), I show that the asymmetries observed in "double" dislocation constructions are still observed if animacy is controlled for. For example, in Zulu constructions with two dislocated inanimate object-DPs, the beneficiary is still the only DP that can be object-marked:

1S-DJ-9.OM-buy-APPL-FV AUG-9-house 9.POSS-my AUG-5.window

'I am buying a window for my house.'

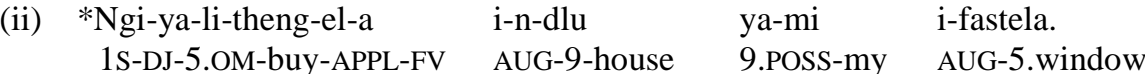

Intended: 'I am buying a window for my house.'

(Zeller 2015: 26)

Note also that an analysis which assumes that animacy is responsible for the asymmetries in (11) and (12) cannot explain why object agreement with the inanimate theme-DP is possible in (8b), despite the presence of an animate beneficiary-DP.

${ }^{8}$ Chomsky (2000: 123) argues that the [i甲]-features of a higher DP can prevent an Agree-relation between a Probe and a lower DP even when the higher DP is inactive as a result of its Case features having been checked and deleted (a so-called "defective intervention effect"). The Zulu data show that DPs that are inactive due to the absence of $[\mathrm{uK}]$ do not produce defective intervention effects; they are truly invisible in terms of Agree-relations.
} 
In an attract-based account, the difference between (13) and (14) would have to be encoded through features on the attracting head $v$ : presumably, in "double" right dislocation constructions such as (11), $v$ would have two EFs, so that both DPs can be attracted to multiple specifiers of $v$. However, it is unclear why the presence of a second EF on $v$ would make a difference for Agree: why would the Probe [u $\varphi]$ of $v$ be able to ignore the [i $\varphi$ ] of the beneficiary when $v$ has only one EF, but not when it has two? There seems to be no (nonstipulative) way in which an analysis that captures movement in terms of attracting features can explain the agreement difference observed above.

The Zulu data therefore provide empirical evidence in favour of a Bošković/Stroik-type analysis of movement as driven by features of the moved element. In addition, the data demonstrate that the same feature $[\mathrm{uK}]$ can simultaneously activate an element for movement and for Agree. Interestingly, in this respect, my analysis contradicts Bošković (2007), who argues (pace Chomsky $(2000,2001)$ ) that the activity condition does not hold for Agree. However, it is clear that this position cannot be maintained in light of the Zulu data. In Zulu, it is exactly the same property of an object that causes it to move out of the VP that also turns it into an active Goal for a Probe in $v$.

Finally, my analysis also sheds an interesting new light on the scope of Locality constraints. Recall that the two dislocated objects in examples such as (11) can appear in either order. One possible interpretation of this fact is that $\mathrm{A}^{\prime}$-movement, in contrast to Agree, is not subject to Locality. Suppose that the first dislocated object moves to a specifier of $v$, and that the second object tucks in below the first. According to this assumption, the word order beneficiary > theme in (11a) is derived when the theme-DP moves first, crossing the beneficiary, which then moves in a second step and tucks in below the theme. The word order theme > beneficiary would result from the opposite order of the two movement steps. According to this analysis, multiple dislocation operations always arrange dislocated objects in the same hierarchical order, but different word order possibilities exist because the order of the dislocation movements is free. ${ }^{9}$ However, this view implies that, even though a beneficiaryDP with [uK] blocks Agree between $v$ and a theme-DP (because [uK] activates the beneficiary-DP for $\varphi$-feature agreement), it does not block movement of the theme to [Spec, $v$ ] (because movement is not triggered by a feature of the probing head $v$ ). Importantly, this asymmetry between agreement and movement is predicted in a theory in which only Agree is a relation between a feature of a higher functional head and a phrase in its c-command domain, whereas movement is a Last Resort operation driven by a feature of the moved phrase. Consequently, only the former operation is expected to show intervention effects of the sort captured by Locality as defined in (10).

\footnotetext{
${ }^{9}$ If multiple specifiers are created not by tucking-in, but by moving the second DP into a specifier above the first, then it would be the word order theme > beneficiary that is derived by moving the theme first, across the beneficiary-DP. Notice that the analysis described in the text differs from how the free word order of two dislocated objects is derived in Zeller (2015). There I assume that the agreeing object (the beneficiary) always moves first, and that the theme-DP can "choose" between different landing sites, one preceding (below) and one following (above) the beneficiary. However, in light of my conclusion that movement is not triggered by features of the target, I now consider the analysis described in the text (which was first suggested to me by Erich Groat) as superior.
} 


\subsection{Left dislocation and object agreement}

I now want to show that the activation of object-DPs through a "mobility" feature $[\mathrm{uK}]$ is not only observed with right dislocation, but in all A'-movement constructions in Zulu. Consider first left dislocation. Left-dislocated objects in Zulu obligatorily agree with the verb; in double object constructions, either object can be left-dislocated:

$\begin{array}{llll}\text { a. U-Sipho } & \text { ngi-m-theng-el-a } & \text { u-bisi. } \\ & \text { AUG-1a.Sipho } & \text { 1s-1.OM-buy-APPL-FV } & \text { AUG-11.milk } \\ \text { 'Sipho, I'm buying him milk.' } & \\ \text { b. } & \text { U-bisi } & \text { ngi-lu-theng-el-a } & \text { u-Sipho. } \\ & \text { AUG-11.milk } \quad \text { 1s-11.OM-buy-APPL-FV } & \text { AUG-1a.Sipho } \\ & \text { 'The milk, I'm buying it for Sipho.' }\end{array}$

Due to the phasehood of $v \mathrm{P}$, I assume that left dislocation proceeds successive-cyclically through the edge of $v \mathrm{P}$. Furthermore, I assume that left-dislocated phrases move to the specifier of a category in the left periphery (which I call Top).

It is possible in Zulu to left-dislocate one object and to right-dislocate the other. Importantly, in these constructions, we find that only the beneficiary-DP can trigger object agreement, $(16)-(17):^{10}$
a.
U-Sipho
ngi-ya-m-theng-el-a
u-bisi.
AUG-1a.Sipho 1S-DJ-1.OM-buy-APPL-FV AUG-11.milk
'Sipho, I am buying (it) for him, the milk.'
b. U-bisi ngi-ya-m-theng-el-a u-Sipho.
AUG-11.milk 1S-DJ-1.OM-buy-APPL-FV AUG-1a.Sipho
'The milk, I am buying (it) for him, Sipho.'

(17)
a. *U-Sipho ngi-ya-lu-theng-el-a u-bisi.
AUG-1a.Sipho 1S-DJ-11.OM-buy-APPL-FV AUG-11.milk
'Sipho, I am buying (it) for him, the milk.'
b. \%*U-bisi ngi-ya-lu-theng-el-a u-Sipho.
AUG-11.milk 1S-DJ-11.OM-buy-APPL-FV AUG-1a.Sipho
'The milk, I am buying (it) for him, Sipho.'

The disjoint verb form signals that both DPs have moved out of the VP in (16) and (17). As (16) shows, it does not matter which object ends up in the left periphery and which one is dislocated to the right. In (16a), the beneficiary has undergone successive-cyclic movement to [Spec, Top] via [Spec, v], while the theme has moved to a second [Spec, $v]$ and stayed there. In (16b), it is the theme that has undergone successive-cyclic movement to [Spec, Top], while the beneficiary has

\footnotetext{
${ }^{10}$ While (17a) shows that it is clearly not possible to left-dislocate the beneficiary when the agreeing theme is right-dislocated, judgements were not quite so clear with respect to examples of the type in (17b), with a rightdislocated beneficiary and an agreeing left-dislocated theme. Although most of the examples of this type were also rejected by my two Zulu consultants (as expected), both speakers were generally less certain about their judgements regarding this construction. Each speaker also unexpectedly accepted one example of this type (although a different one in each case). To reflect this situation, I have marked (17b) as \%*. I have no explanation for why examples of the (17b)-type were not systematically excluded, whereas judgements regarding the ungrammaticality of examples such as (17a) were robust.
} 
remained in [Spec, v]. However, object agreement is again constrained by Locality when both DPs have moved out of the VP: in this case, only the beneficiary-DP can be object-marked.

The contrast between (15b), which shows that object agreement with the theme is possible when the beneficiary has remained inside the VP, and (17), where both DPs are dislocated, follows from the analysis outlined in section 3.1. Moved DPs have [uK] in Zulu, and only phrases with $[\mathrm{uK}]$ are active for object agreement. Therefore, object agreement with the theme is possible when only the theme is left-dislocated, because the beneficiary does not have [uK]. In contrast, when the beneficiary is also dislocated, it intervenes as an active Goal between $v$ and the theme-DP and blocks object agreement with the latter.

\subsection{Relative clauses and object agreement}

In Zulu relative clauses, a null relative operator $(O p)$ moves to [Spec, $\mathrm{C}$ ]. When the extracted operator corresponds to an object, object marking is usually obligatory (Zeller 2004, 2006):

(18) A-ba-ntu [OP e-ngi-*(ba)-thanda-yo] ba-ya-hamb-a.

AUG-2-person 2.Op REL-1s-2.OM-like-RS 2.SM-DIS-leave-FV

'The people I like are leaving.'

If the relative clause is based on a ditransitive verb, either object can be relativised (Zeller 2014):
A-ba-ntwana
AUG-2-child
[Op o-ba-nik-e
i-zin-cwadi] ba-ya-jabul-a.
2.Op REL.2S-2.OM-give-PST AUG-10-book
'The children to whom you gave the books are happy.'
b. I-zin-cwadi $\left[\begin{array}{ll}O p & \text { o-zi-nik-e a-ba-ntwana }]\end{array}\right.$
AUG-10-book 10.Op REL.2s-10.OM-give-PST AUG-2-child
'The books that you gave the children are red.'
2.SM-DJ-be.happy-FV
zi-bomvu.
10.SM-red

(Zeller 2014: 362)

I assume that the null operator in the examples in (18) and (19) has moved to [Spec, C] of the relative clause successive-cyclically via the phase edge [Spec, v]. Since movement is triggered by $[\mathrm{uK}]$, and the non-relativised object has remained in the VP, [u $\varphi$ ] on $v$ can see the $\varphi$-features of the null operator (which correspond to those of the head noun) as its closest Goal and agrees with them. Consequently, object agreement in Zulu relatives is with the relative operator.

My analysis predicts that in relative clauses with one dislocated and one relativised object, object marking should only be possible with the beneficiary. The problem is that this prediction is difficult to test with full DPs in Zulu, since object right dislocation in object relative clauses is a highly marked strategy. My consultants generally did not judge any examples as acceptable in which one object of a ditransitive verb was relativised and the other one right-dislocated. 
However, the picture changes slightly when the dislocated object is the phonologically null pronominal pro. As shown in (20), pro-objects trigger object agreement and are obligatorily dislocated in Zulu: ${ }^{11}$
(20) U-Langa u-ya-ba-phek-el-a] $]_{\mathrm{VP}}$ pro AUG-1a.Langa 1.SM-DJ-2.OM-cook-APPL-FV 2.pro 'Langa is cooking for them.'

Buell (2005) shows that it is possible in Zulu to relativise one object of a double object construction and to realise the other one as pro. In (21), the beneficiary argument is pro (noun class 1), which agrees with the verb. The theme (class 9) has been relativised, but does not agree:
(21) Y-i-mali
[[Op e-ngi-m-nik-ile-yo $]_{\mathrm{VP}}$
pro]
COP-AUG-9.money 9.Op REL-1S-1.OM-give-DJ.PST-RS 1.pro
'It's money that I gave him.'

[Buell 2005: 177; bracketing added]

Furthermore, Zeller (2014) demonstrates that it is also possible to relativise the beneficiary and to realise the theme as pro. In this case, object agreement must be with the relative operator:
(22) A-ba-ntwana $\left[[\boldsymbol{O P} \text { o-ba-nik-ile }]_{V P}\right.$ pro] ba-ya-jabul-a. AUG-2-child 2.Op REL.2s-2.OM-give-DJ.PST 10.pro
2.SM-DJ-be.happy-FV 'The children to whom you gave them are happy.'

(Zeller 2014: 363)

However, Zeller (2014) also shows that the option of realising both objects as null elements is not systematically available. Even for those speakers who accept data such as (21) and (22), ${ }^{12}$ the following constructions are unacceptable:

\footnotetext{
${ }^{11}$ Due to the lack of phonetic content, the claim that pro is obligatorily dislocated is difficult to prove. However, pro-dislocation follows from the general requirement that material that is not part of the focus has to vacate the VP in Zulu (see Cheng and Downing 2009; Zeller 2015). Since pro is a weak pronoun and refers to a discoursegiven entity, it cannot be focused and can therefore not remain in the VP. The cross-linguistic tendency of weak pronouns to undergo object shift and to move out of the VP is well-known, and has been widely discussed in the literature, in particular with respect to the Scandinavian languages (cf. Holmberg 1986).

${ }^{12}$ As noted in Zeller (2014), not all speakers accept relative clause constructions such as (21) and (22) in which either the null relative operator or pro is left without an agreement reflex. The standard strategy in Zulu object relatives based on double object constructions with a pronominalised object is to realise the latter as a strong pronoun. However, as I observe in Zeller (2014), those speakers who accept examples such as (21) and (22) still reject the examples in (23), which is clear evidence that the contrast observed in dislocation constructions also holds in relative clauses.
} 
In (23a), the theme has been relativised, and the beneficiary is pro. In this respect, (23a) is similar to the grammatical example in (21). The example in (23b) resembles (22) in that the theme is pro and the beneficiary is the relative operator. However, (23a) and (23b) are both ungrammatical. This is because the verbs in the relative clauses in (23), in contrast to the constructions in (21) and (22), show object agreement with the theme. This ungrammaticality is predicted by my analysis. Since both pro and the relative operator have been moved out of the VP in these examples, they must both be marked as $[\mathrm{uK}]$. The $\varphi$-features of both objects are therefore active for Agree, and Locality determines that object agreement must be with the higher object (the beneficiary). Object agreement with the theme is possible only when the beneficiary has remained inside the VP (see (19b) above). In this case, the beneficiary lacks $[\mathrm{uK}]$ and is not an active Goal in terms of Locality; when the theme is relativised, it can therefore agree with $v$.

\section{4 $[\mathrm{uK}]$ and covert movement}

The final type of $\mathrm{A}^{\prime}$-movement that I will discuss here is Quantifier Raising (QR). ${ }^{13}$ The difference between $\mathrm{QR}$ and the types of $\mathrm{A}^{\prime}$-movement discussed above is that $\mathrm{QR}$ takes place in covert syntax. Nevertheless, if all movement is driven by an uninterpretable feature $[\mathrm{uK}]$, then we also expect to observe the effects of this feature with QR, especially if QR is analysed as an instance of overt movement plus spell-out of the lower copy (as suggested by Fox and Nissenbaum 1999, among others).

If $\mathrm{QR}$ is movement driven by a [uK]-feature, then the analysis proposed above makes two predictions. Firstly, quantified objects should obligatorily trigger object agreement in Zulu, even when they are pronounced inside the VP. However, (24) shows that this is not the case:

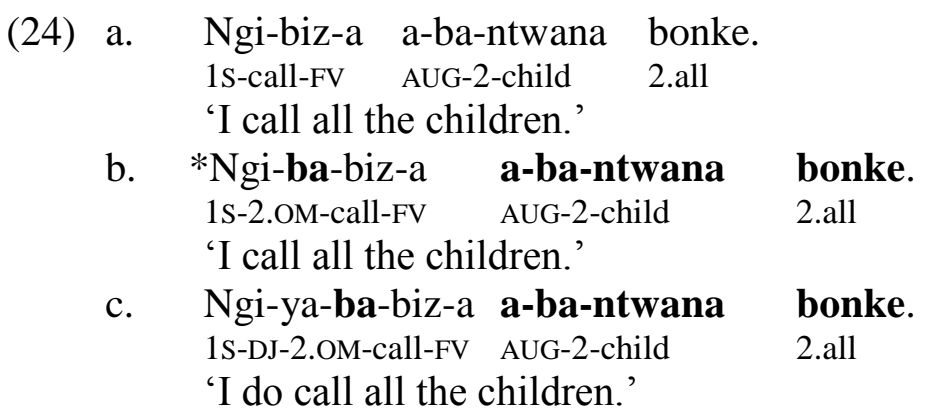

If QR was indeed triggered by $[\mathrm{uK}]$, then object quantifiers should always trigger object agreement because, as I have argued, $[\mathrm{uK}]$ activates an element as a possible Goal for object agreement. However, as (24a) shows, a non-agreeing object-QP is perfectly fine in Zulu. Moreover, object agreement is even ruled out when the object-QP is pronounced inside the VP, as (24b) shows; like ordinary object-DPs, a QP has to undergo overt dislocation in order to agree, as shown by (24c) (note that the obligatoriness of the disjoint marker $y a$ - in $(24 \mathrm{c})$ is evidence that the QP is outside VP). ${ }^{14}$

\footnotetext{
${ }^{13}$ Notice that Zulu does not have wh-movement; wh-ex situ constructions are realised as clefts (Sabel and Zeller 2006).

${ }^{14}$ The example in (24b) is based on the judgement of my consultants, who rejected object marking with in situ quantifiers. However, it is interesting that Voeltz (2004: 12) reports example (24b) to be grammatical. In fact, according to the discussion in Voeltz (2004), quantifiers would be systematic exceptions to the general rule that
} 
The second prediction (noted by Tarald Taraldsen p.c.) is that a beneficiary QP should always block Agree between $v$ and the theme. Again, this prediction is not borne out:

(25) Ngi-lu-theng-el-a i-zin-gane zonke u-bisi.

1s-11.OM-buy-APPL-FV AUG-10-child 10.all AUG-11.milk

'I'm buying it for all the children, the milk.'

The example in (25) shows that the quantified beneficiary does not block object agreement with a right-dislocated theme. However, if $\mathrm{QR}$ was driven by $[\mathrm{uK}]$ of $\mathrm{Q}$, then we would expect (25) to be ungrammatical, since the QP's [uK] feature would be closer to the Probe in $v$ than the $[\mathrm{uK}]$ of the theme, and it would intervene in terms of Locality.

The data in (24) and (25) lead me to conclude that QR in Zulu is not driven by a feature [uK]. However, this conclusion does not raise a problem for the analysis proposed above. As I discuss now, QR is in fact triggered by a property of the moved QP (and therefore does not require the postulation of attracting features), but this property is not a syntactic feature. Rather, Lechner $(2009,2012)$ shows that in the case of $\mathrm{QR}$, it is the semantic type of quantifiers that causes QPs to be repelled from their base position.

Lechner (2012: 5) argues that QR is triggered by type incompatibility, defined as in (26b):

(26) Type (in) compatibility

a. A node $\alpha$ is type compatible iff the denotation of $\alpha$ and its sister can be combined by the principles of semantic composition (Function Application, Predicate Modification, etc.)

b. $\quad \alpha$ is type incompatible otherwise

As is well-known, generalised quantifiers have the semantic type $\langle<\mathrm{e}, \mathrm{t}\rangle,\langle<\mathrm{e}, \mathrm{t}\rangle, \mathrm{t}\rangle\rangle$; QPs such as every linguist or all children have the semantic type $\langle<\mathrm{e}, \mathrm{t}\rangle, \mathrm{t}\rangle$ (they map properties onto truth-values). Therefore, when an object-QP is merged with a transitive verb of type $\langle\mathrm{e},\langle\mathrm{e}, \mathrm{t}\rangle\rangle$, the resulting structure cannot be interpreted; the object-QP and the verb in (27) are type incompatible:

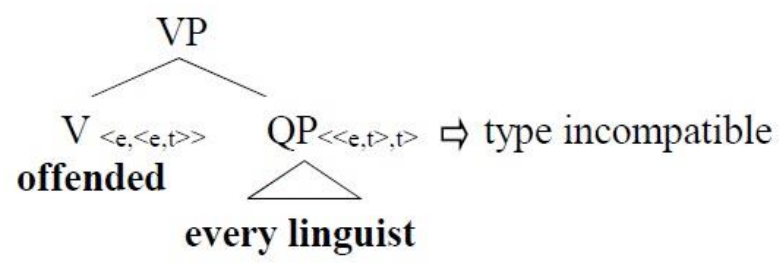

However, the problem raised by (27) can be solved by QR. When the QP moves, it leaves behind a copy (or trace) that is interpreted as a variable of type $\langle\mathrm{e}\rangle$, which can serve as an argument of the verb (see Heim and Kratzer 1998 and section 4.2 below):

agreeing objects must be dislocated in Zulu. Voeltz's (2004) observation, if accurate, would be relevant for my analysis here, but unfortunately, I could not reproduce the judgements he reports with my consultants. Therefore, I have to assume that examples such as (24b) are ungrammatical in Zulu. 


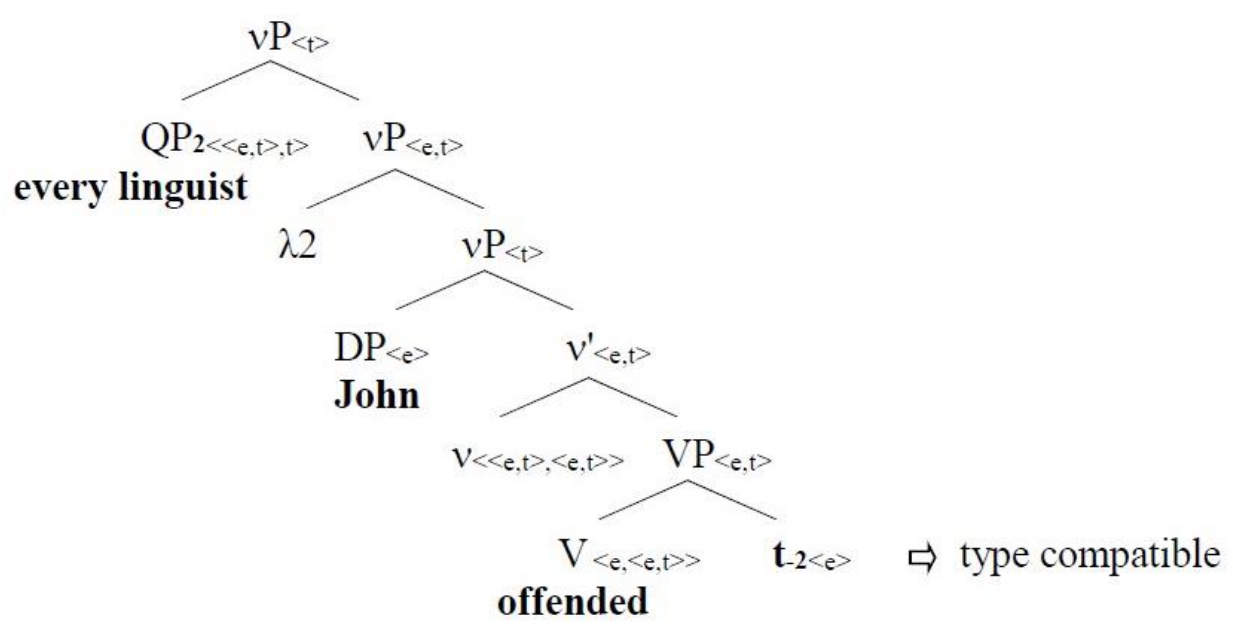

(28) illustrates the type-driven derivation of a sentence like John offended every linguist, in which the object-QP has undergone QR by moving to the edge of $v \mathrm{P} .{ }^{15}$ This movement is not caused by an uninterpretable grammatical feature, but can be analysed as being driven by the fact that a structure with an in situ QP cannot be interpreted. Therefore, according to Lechner (2009, 2012), type incompatibility forces QR.

Notice that the semantic type of the quantifier also determines the landing site of QR: The QP in (28) must at least merge as high as $\nu \mathrm{P}$. This is because $\mathrm{QR}$ introduces a $\lambda$-operator that binds the variable left behind by QR. Only if the $\lambda$-operator combines with a constituent of type $\langle t\rangle$ is the resulting constituent of type $\langle e, t\rangle$ and hence a suitable argument for the quantifier (see Cable 2011; Heim and Kratzer 1998; Lechner 2009, 2012). I return to this point in section 4.2 .

In conclusion, $\mathrm{A}^{\prime}$-movement can be triggered by different properties of the moved element. A phrase may be repelled from its base position either because it has a syntactic feature that cannot be checked and deleted without movement, or because its semantic type makes it uninterpretable in its base position. Both properties may also be simultaneously realised on a phrase, for example in constructions such as $(24 \mathrm{c})$, where the quantifier is overtly dislocated. Importantly, Agree in Zulu is only sensitive to [uK]. Therefore, instances of QR that are only triggered by type incompatibility do not show agreement reflexes. ${ }^{16}$

\section{The nature of $[\mathrm{uK}]$}

I have shown that in Zulu, the mobility feature $[\mathrm{uK}]$ activates an element $\mathrm{Y}$ for both movement and Agree. According to Bošković's (2007) theory discussed in section 2.2, Y with

\footnotetext{
${ }^{15}$ In (27) and (28), I have glossed over some details, for example by representing the verb as a function of type $\langle\mathrm{e},\langle\mathrm{e}, \mathrm{t}\rangle\rangle$, and by representing the type of $v$ in $(28)$ as $\langle\langle\mathrm{e}, \mathrm{t}\rangle,\langle\mathrm{e}, \mathrm{t}\rangle\rangle$ (which guarantees that the semantic type of the VP is passed on to the next node $v^{\prime}$ ). However, in the MP, the external argument is not considered to be an argument of the verb, but of $v$. The denotations of $\mathrm{V}$ and $v$ would have to be adjusted to capture this fact. See Kratzer (1996) for a possible implementation in a neo-Davidsonian event semantics framework.

${ }^{16}$ Given that [uK] seems to be associated with all instances of overt A'-movement, it is tempting to speculate that $[\mathrm{uK}]$ is somehow linked to spell-out rules at PF. Perhaps chains with [uK] require spell-out of their head, while (non-trivial) chains without [uK] have to be spelled-out at the tail. Since [uK] is typically absent from QPs, QR is usually "covert".
} 
$[\mathrm{uK}]$ must move because $[\mathrm{uK}]$ is a Probe that needs to c-command a suitable Goal in order to be checked and deleted. But what is the nature of $[\mathrm{uK}]$, what is the nature of the Goal, and how exactly is $[\mathrm{uK}]$ checked? In the following two subsections I discuss two possible accounts that provide slightly different answers to these questions.

\subsection{Different types of [uK]}

An element $\mathrm{Y}$ with $[\mathrm{uK}]$ must move to bring $[\mathrm{uK}]$ into a position from where it can probe its c-command domain for a corresponding feature that can act as a Goal. A plausible assumption is that a suitable Goal for [uK] is an interpretable feature of the same type as [uK], i.e. [iK]. If this Goal-feature is located on a head X, then the closest position to which Y can move for its $[\mathrm{uK}]$-feature to be checked is [Spec, $\mathrm{X}]$.

In section 3, I discussed three types of $\mathrm{A}^{\prime}$-movement of object-DPs in Zulu: movement to [Spec, v] (right dislocation), movement to [Spec, Top] (left dislocation), and movement to [Spec, C] (relativisation). One assumption that would explain these different movement operations is that the relevant functional head that provides the target for movement carries an interpretable feature that can act as a Goal for [uK]. For example, in left dislocation, one could postulate a feature [iTopic] on the Top-head. The motivation for object left dislocation would then follow from the presence of $[\mathrm{uK}]=[\mathrm{uTopic}]$ on the object-DP, which needs to move out of the VP and at least as high as [Spec, Top], so that [uTopic] can probe and find [iTopic]. Similarly, right dislocation and relativisation could also be associated with specific interpretable features on $\mathrm{C}$ and $v$; their uninterpretable counterparts are associated with DPs as different instantiations of $[\mathrm{uK}]$. While the versions of $[\mathrm{uK}]$ that trigger movement of a phrase to [Spec, $v]$ or [Spec, Top] are optionally associated with a phrase (since right and left dislocation are optional), the feature that causes movement to [Spec, $\mathrm{C}$ ] in relative clauses is inherently part of the feature matrix of the null relative operator, and therefore will trigger obligatory operator movement.

Recall that left dislocation and relativisation proceed successive-cyclically, via [Spec, v], the phase edge. However, as noted in section 2.2, this intermediate movement step is not driven by a feature of the phase head. As argued by Bošković (2007), when [uK] appears inside a phase that does not include a matching Goal for $[\mathrm{uK}]$, then the phrase with $[\mathrm{uK}]$ needs to move to the phase edge to be accessible for operations in the next phase, anticipating that the next phase includes a suitable Goal. For example, when an object-DP in Zulu has [uTopic], it will have to move to [Spec, v] by Last Resort, because otherwise [uTopic] will remain unchecked. In the next phase, when Top with [iTopic] is merged, the DP will move to [Spec, Top] from where it c-commands Top, and [uTopic] can be checked and deleted.

According to this analysis, then, there are different types of $[\mathrm{uK}] .[\mathrm{uK}]$ is the uninterpretable counterpart of an interpretable feature associated with either $v, C$, or Top. If any one of these different versions of the $[\mathrm{uK}]$-feature is realised on an object-DP, then this DP will have to move out of the VP and, depending on the nature of [uK], will undergo left dislocation, right dislocation, or relativisation.

Note that this analysis implies that the final landing site of a phrase $Y$ is already predetermined by the specific type of $[\mathrm{uK}]$ on $\mathrm{Y}$ before $\mathrm{Y}$ starts moving. However, it would perhaps be conceptually more attractive to assume that there is only one general type of $[\mathrm{uK}]$ 
that marks an element $\mathrm{Y}$ as mobile, but without specifying where $\mathrm{Y}$ will have to move, and to establish the final landing site of $\mathrm{Y}$ in the course of the derivation. In the final part of this paper, I show how this alternative idea can be captured theoretically.

\subsection{Movement and index interpretation}

In section 3.4, I discussed the semantics of QR. I showed that when QR raises a QP which then merges with a higher node, its sister node is interpreted as a function of type $\langle e, t\rangle$, which is a possible argument for the semantics of the QP. The correct semantic type of the QP's sister node is derived by assuming that $\mathrm{QR}$ introduces a $\lambda$-operator into the semantics that binds the variable left behind by QR. In (28) in section 3.4, I have represented this idea informally, by adding the $\lambda$-operator to the syntactic tree diagram. However, note that strictly speaking, the $\lambda$-operator is not part of the syntax; it is only added in the semantic component. What is part of the syntax is the index of the moved element. It is commonly assumed by "semantically-minded syntacticians" (Cable 2011: 3) that QR gives rise to a process called "index copying" through which the index of a raised QP is introduced as a separate node in the syntax (Cable 2011; Heim and Kratzer 1998):

(29) Index copying

The index of the moved phrase is copied as a sister to the sister of the moved phrase.

(Cable 2011: 3)

According to (29), the "proper" syntax of a construction such as (30a), in which a QP has raised and adjoined to XP, looks like (30b), with the movement index of the QP added below XP: ${ }^{17}$
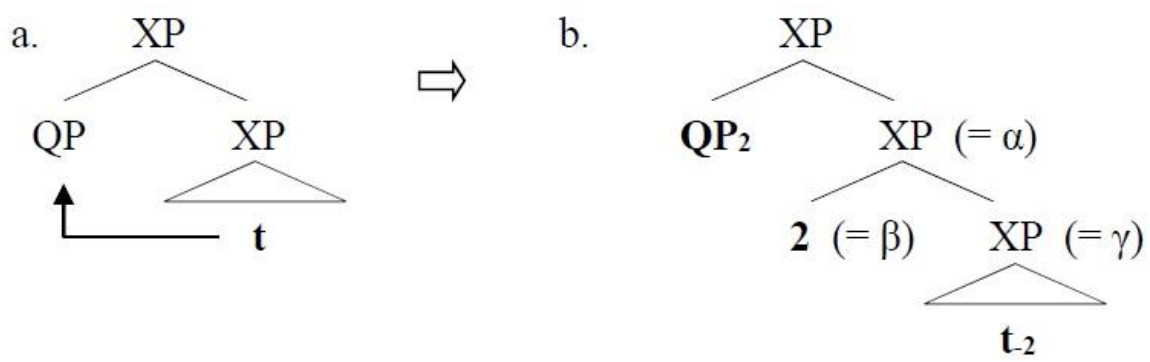

The syntax in (30b) is then interpreted at LF according to the following Predicate Abstraction Rule PA (see Cable (2011: 6) and Heim and Kratzer (1998: 186) for slightly different formulations of PA):

(31) Predicate Abstraction Rule (PA)

Let $\alpha$ be a branching node with daughters $\beta$ and $\gamma$, where $\beta$ is the numerical index $i$. Then, for any variable assignment $\mathrm{a},[[\alpha]]^{\mathrm{a}}=\lambda \mathrm{x}_{\langle\mathrm{e}\rangle} \cdot[[\gamma]]^{\mathrm{a}(\mathrm{x} / \mathrm{i})}$.

\footnotetext{
17 The process of index copying violates the Inclusiveness Condition (IC; Chomsky 1995: 228), which demands that "no new objects are added in the course of computation". However, it is not clear how the syntax of movement constructions can be interpreted compositionally without the assumption that movement adds interpretable indices. Therefore, I adopt index copying here, even if it violates the IC.
} 
The notation a(x/i) in (31) refers to a modified variable assignment, which is identical to assignment a except that it assigns $\mathrm{x}$ to the index $\mathrm{i}$. When PA is applied to the XP-node that dominates the index 2 in (30b), the modified variable assignment will ensure that $\mathrm{x}$ is associated with the trace of the moved QP, which bears the same index, and $\mathrm{x}$ is then bound by the $\lambda$-operator. Furthermore, because $\mathrm{x}$ is of semantic type $\langle\mathrm{e}\rangle$, and the lowest XP-node in $(30 \mathrm{~b})(=\gamma)$ denotes an expression of type $\langle\mathrm{t}\rangle$, PA determines that the denotation of the higher $\mathrm{XP}$-node $(=\alpha)$ is of type $<\mathrm{e}, \mathrm{t}>$. Since the semantics of the QP is of type $<<\mathrm{e}, \mathrm{t}>, \mathrm{t}>$, it can take the denotation of this XP-node as an argument:

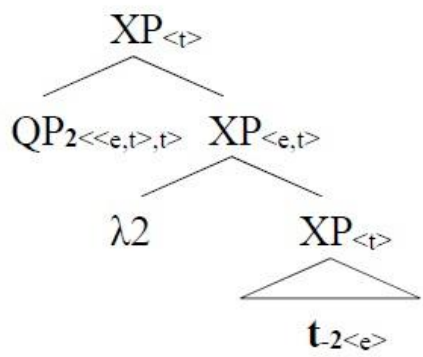

Importantly, the process of index copying and the PA-rule are not only necessary for QR. Rather, all types of A'-movement (and arguably also A-movement) require index copying. For example, when a DP of type $<\mathrm{e}>$ is topicalised, it is interpreted in its final landing site [Spec, Top]. However, this means that the DP combines with a node of type $\langle t\rangle$. Index copying and PA are hence also required in this case to turn the denotation of the DP's sister node into a function that can take the denotation of the moved DP as an argument (see Cable 2011):

(33) John, I like.

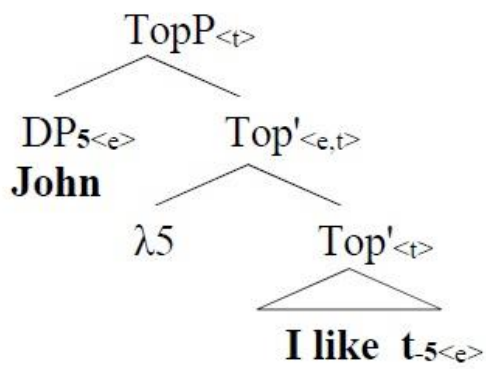

I now propose that the (interpretable) Goal "feature" that can check and delete [uK] on a moved element is the index that is copied into the syntax in $\mathrm{A}^{\prime}$-movement constructions. When a phrase $\mathrm{Y}$ with $[\mathrm{uK}]$ moves to a position in which it is also interpreted, then its feature $[\mathrm{uK}]$ is deleted automatically, since the very fact that $\mathrm{Y}$ is interpreted in this position requires that its index is copied into the c-command domain of $\mathrm{Y}$. In other words, [uK] activates a phrase $\mathrm{Y}$ for movement, because only movement can introduce an interpretable index as a potential Goal for $[\mathrm{uK}]$ in the c-command domain of $\mathrm{Y}$. Note that therefore, the final landing site of movement of $\mathrm{Y}$ with $[\mathrm{uK}]$ is always the position in which $\mathrm{Y}$ is interpreted, since in this position, the interpretable index will automatically act as a Goal, and [uK] will be checked and deleted. Y can no longer move after it is interpreted, since the feature that activates $\mathrm{Y}$ for movement is no longer present. 
The properties of successive-cyclic $\mathrm{A}^{\prime}$-movement also follow from this analysis. When a phrase $\mathrm{Y}$ with $[\mathrm{uK}]$ appears inside a phase $\alpha$, it will have to move to the edge of $\alpha$ before Transfer. For $\mathrm{Y}$ to be interpretable in this position, its index will have to be copied into the structure, in which case $[\mathrm{uK}]$ will be checked and deleted, and no further movement will take place. However, suppose $\mathrm{Y}$ is not interpreted at the edge of $\alpha$. In this case, no index is copied, $[\mathrm{uK}]$ survives, and $\mathrm{Y}$ remains active for movement into a position in the next phase:

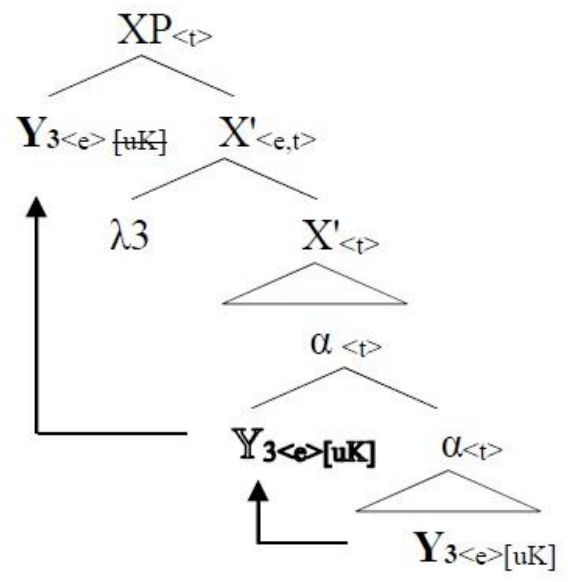

When Y's index is not copied into the edge of $\alpha$, no $\lambda$-operator will be introduced into the semantics. In this case, $Y$ will not be interpretable in this position, since $Y$ and its sister node are now type incompatible. But this means that, for the derivation not to crash at LF, the intermediate copy of $\mathrm{Y}$ has to be ignored by the semantic rules that interpret the representation in (35). What follows from this is the well-known fact that only the head and the tail of an A'-chain are interpreted in a derivation, while intermediate copies are "invisible at LF" (Chomsky 1995: 301), as indicated by the outline font in (35).

According to this alternative proposal, there is only one type of $[\mathrm{uK}] .[\mathrm{uK}]$ is an uninterpretable feature of a phrase $\mathrm{Y}$ that is automatically checked in the position in which $\mathrm{Y}$ is interpreted. The checker is the index that is copied into the c-command domain of $\mathrm{Y}$ when $Y$ has moved and that receives an interpretation as a $\lambda$-operator at LF (see (29) and (31)). Since the index is introduced through movement, $[\mathrm{uK}]$ can never be checked when $\mathrm{Y}$ is in situ, which is why $[\mathrm{uK}]$ activates $\mathrm{Y}$ for movement. As long as $[\mathrm{uK}]$ remains on $\mathrm{Y}, \mathrm{Y}$ will move up in the derivation, until it lands in a position in which it is interpreted.

Before I conclude this section, it is worth pointing out that the proposal outlined here is based on the assumption that a moved DP, in principle, can be interpreted at any point in the derivation where it merges with a node of type $\langle\mathrm{t}\rangle$. Whether or not interpretation and index copying happen at a particular stage depends on extra-linguistic factors (such as the speaker's communicative intention), and not on the syntax. However, once a moved element is interpreted in a specific position, the syntactic derivation comes to a halt, since the feature that drives movement will be checked and deleted in this position. Note that with respect to the question of how syntax and semantics interact, the proposal outlined here is therefore different from the system proposed in Chomsky (2008), which was briefly discussed in section 2.1. In Chomsky's (2008) model, $\mathrm{A}^{\prime}$-movement is triggered by the presence of optional EFs on phase heads; the highest phase head with EF is therefore the highest position in which a moved element can appear. According to Chomsky (2008), the interpretation of the 
moved element is then established on the basis of the final position it has reached - the semantics is "read off" the syntax. In contrast, in the model described in this section, the interpretation of a moved element in a particular position determines (via index copying and $[\mathrm{uK}]$-feature checking) that this is also the final landing site of the moved element. In this respect, syntactic derivations depend on the intended interpretation, and the final syntactic position of a moved element is a consequence of the semantics, not the other way around.

In this section, I have discussed two possible ways in which the idea of a mobility feature can be fleshed out. The (more traditional) account I have provided in section 4.1 is based on the standard view that an uninterpretable feature is checked by a corresponding syntactic feature of the same type that is associated with a particular functional head in the syntax. The alternative proposal in section 4.2 instead assumes that the checker of [uK] is not a syntactic feature in the traditional sense, but the index of the moved element $\mathrm{Y}$ that is introduced into the syntax in the position in which $\mathrm{Y}$ is interpreted. At present, I consider both proposals potentially viable, but I hope that future research will reveal which one is better suited to account for the properties of $\mathrm{A}^{\prime}$-movement constructions in natural language.

\section{Conclusion}

If syntactic movement is feature-driven, then there are two possibilities: a moved element can be attracted by a feature of the target, or it can be pushed up by one of its own features when this feature needs to be in a syntactically higher position for checking purposes. I have shown that the empirical properties of A'-movement in Zulu support the latter of these two options. In Zulu, the probing [u $\varphi$ ]-features of $v$ will only identify $\varphi$-features of a DP as a suitable Goal if that DP also undergoes movement. However, while [u $\varphi$ ] of $v$ probes its c-command domain, the landing site of $\mathrm{A}^{\prime}$-movement is outside the c-command domain of the Probe. This means that the Probe must be able to "see" that a DP is "earmarked for movement" even before the DP is moved and remerged in a higher position. The conclusion that follows from this fact is that the "I am moving!"-property of a dislocated or relativised DP in Zulu cannot be captured by means of attracting features, but must be a property of the DP itself.

\section{References}

Adams, N. 2010. The Zulu ditransitive verb phrase. $\mathrm{PhD}$ thesis, The University of Chicago.

Bošković, Ž. 2002. A-movement and the EPP. Syntax 5(3): 167-218.

Bošković, Ž. 2007. On the Locality and Motivation of Move and Agree: An Even More Minimal Theory. Linguistic Inquiry 38(4): 589-644.

Bošković, Ž. 2014. Now I'm a Phase, Now I'm Not a Phase: On the Variability of Phases with Extraction and Ellipsis. Linguistic Inquiry 45(1): 27-89.

Buell, L. 2005. Issues in Zulu Verbal Morphosyntax. Ph.D. thesis, Los Angeles, CA: UCLA.

Buell, L. 2006. The Zulu Conjoint/Disjoint Verb Alternation: Focus or Constituency? In L. Downing, L. Marten and S. Zerbian (Eds.) Papers in Bantu Grammar and Description. ZAS Papers in Linguistics 43. Berlin: ZAS. pp. 9-30. 
Cable, S. 2011. The semantics of movement and relative clauses. Class handout Semantics and Generative Grammar, Fall 2011, University of Massachusetts at Amherst.

Cheng, L. and L. Downing. 2009. Where's the Topic in Zulu? The Linguistic Review 26(2): 207-238.

Chomsky, N. 1995. The Minimalist Program. Cambridge, Mass.: The MIT Press.

Chomsky, N. 2000. Minimalist inquiries: the framework. In R. Martin, D. Michaels and J. Uriagereka (Eds.) Step by Step. Cambridge, Mass: The MIT Press. pp. 89-155.

Chomsky, N. 2001. Derivation by Phase. In M. Kenstowicz (Ed.) Ken Hale. A Life in Language. Cambridge, Mass: The MIT Press. pp. 1-52.

Chomsky, N. 2007. Approaching UG from Below. In U. Sauerland and H.M. Gärtner (Eds.) Interfaces + Recursion $=$ Language $?$. Berlin: Mouton de Gruyter. pp. 1-29.

Chomsky, N. 2008. On Phases. In R. Freidin, C. Otero and M.L. Zubizarreta (Eds.) Foundational Issues in Linguistic Theory: Essays in Honor of Jean-Roger Vergnaud. Cambridge, MA: The MIT Press. pp. 133-166.

Chomsky, N. 2013. Problems of projection. Lingua 130: 33-49.

Epstein, S.D., E.M. Groat, R. Kawashima and H. Kitahara. 1998. A derivational approach to syntactic relations. Oxford: Oxford University Press.

Epstein, S.D. and T.D. Seely. 2006. Derivations in Minimalist syntax. Cambridge: Cambridge University Press.

Fox, D. and J. Nissenbaum. 1999. Extraposition and scope: A case for overt QR. In S. Bird, A. Carnie, J.D. Haugen and P. Norquest. (Eds.) Proceedings of the 18th West Coast Conference on Formal Linguistics (WCCFL 18). Somerville, MA: Cascadilla Press. pp. 132-144.

Grewendorf, G. 2001. Multiple wh-fronting. Linguistic Inquiry 32(1): 87-122.

Grohmann, K., J. Drury and J.C. Castillo. 2000. No more EPP. In R. Billerey and B.D. Lillehaugen (Eds.) Proceedings of the 19th West Coast Conference on Formal Linguistics (WCCFL 19). Somerville, MA: Cascadilla Press. pp. 153-166.

Halpert, C. 2012. Argument licensing and agreement in Zulu. Ph.D. thesis, Cambridge, MA: Massachusetts Institute of Technology.

Heim, I. and A. Kratzer. 1998. Semantics in Generative Grammar. Oxford: Blackwell.

Holmberg, A. 1986. Word Order and Syntactic Features in Scandinavian Languages and English. PhD thesis, University of Stockholm. 
Kratzer, A. 1996. Severing the external argument from its verb. In J. Rooryck and L. Zaring (Eds.) Phrase structure and the lexicon. Dordrecht: Kluwer. pp. 109-137.

Lechner, W. 2009. Evidence for Survive from covert movement. In M. Putnam (Ed.) Towards a Derivational Syntax. Survive Minimalism. Amsterdam: John Benjamins. pp. 231-254.

Lechner, W. 2012. Structure building from below: more on Survive and covert movement. In V. Valmala and M. Uribe-Etxebarria (Eds.) Structure Building. Cambridge: Cambridge University Press. pp. 297-329.

Marantz, A. 1993. Implications of asymmetries in double object constructions. In S.A. Mchombo (Ed.) Theoretical aspects of Bantu grammar. Stanford: CSLI Publications. pp. 113-148.

Rizzi, L. 1990. Relativized Minimality. Cambridge: MIT Press.

Sabel, J. and J. Zeller. 2006. Wh-question formation in Nguni. In J. Mugane, J. Hutchison and D. Worman (Eds.) African Languages and Linguistics in Broad Perspective (selected Proceedings of the 35th Annual Conference of African Linguistics). Somerville, MA: Cascadilla Press. pp. 271-283.

Stroik, T. 2009. Locality in Minimalist Syntax. Cambridge, MA: MIT Press.

Van der Spuy, A. 1993. Dislocated noun phrases in Nguni. Lingua 90(4): 335-355.

Voeltz, F.K.E. 2004. Long and short verb forms in Zulu. Ms., University of Cologne.

Zeller, J. 2004. Relative clause formation in the Bantu languages of South Africa. Southern African Linguistics and Applied Language Studies 22(1-2): 75-93.

Zeller, J. 2006. On the relation between noun prefixes and grammaticalisation in Nguni relative clauses. Studia Linguistica 60(2): 220-249.

Zeller, J. 2012. Object marking in isiZulu. Southern African Linguistics and Applied Language Studies 30(2): 219-235.

Zeller, J. 2014. Three types of object marking in Bantu. Linguistische Berichte 239(21): 347-367.

Zeller, J. 2015. Argument prominence and agreement: explaining an unexpected object asymmetry in Zulu. Lingua 156: 17-39. 